\title{
Small and Laterally Placed Incisional Hernias Can be Safely Managed with an Onlay Repair
}

\author{
Rudolf Schrittwieser $^{1} \cdot$ Ferdinand Köckerling $^{2} \cdot$ Daniela Adolf $^{3} \cdot$ Martin Hukauf $^{3}$. \\ Simone Gruber-Blum ${ }^{4} \cdot$ René H. Fortelny $^{4,5} \cdot$ Alexander H. Petter-Puchner ${ }^{4}$
}

Published online: 11 March 2019

(C) The Author(s) 2019

\begin{abstract}
Introduction In meta-analyses and systematic reviews, clear advantages have been identified for the sublay versus onlay technique for treatment of incisional hernias. Nonetheless, an expert panel has noted that the onlay mesh location may be useful in certain settings.

Materials and methods First, unadjusted analysis of data from the Herniamed Registry was performed to compare 6797 sublay operations with 1024 onlay operations for repair of incisional hernias. Then, using propensity score matching to account for the influence of variables age, gender, ASA score, BMI, risk factors, preoperative pain, defect size, and defect localization, 1016 pairs were formed and compared with each other.

Results Unadjusted analysis revealed that the onlay operation was used significantly more often for small defects, lateral defect localization, and in women. After comparing the propensity score-matched pairs, no significant difference was found between the sublay and onlay technique in the outcome criteria intra- and postoperative complications, general complications, complication-related reoperations, pain at rest, pain on exertion, chronic pain requiring treatment, and recurrence on 1-year follow-up. But that was true only for this carefully selected patient collective.

Conclusion In a selected patient collective with small and lateral incisional hernias and with a large proportion of women, outcomes obtained for the onlay and sublay techniques do not differ significantly.
\end{abstract}

Rudolf Schrittwieser and Ferdinand Köckerling contributed equally to this publication.

\section{Ferdinand Köckerling}

ferdinand.koeckerling@vivantes.de

1 Department of General Surgery, Country Hospital Hochsteiermark, Steiermärkische

Krankenanstaltengesellschaft m.b.H., Tragösserstrasse 1 und 1a, 8600 Bruck an der Mur, Austria

2 Department of Surgery, Center for Minimally Invasive Surgery, Academic Teaching Hospital of Charité Medical School, Vivantes Hospital, Neue Bergstrasse 6, 13585 Berlin, Germany

\section{Introduction}

In systematic reviews, the prevalence of incisional hernia after midline incision was $12.8 \%$ (range $0-35.6 \%$ ) at a weighted mean of 23.7 months [1], and with a lower rate of

3 StatConsult GmbH, Halberstädter Strasse 40 a, 39112 Magdeburg, Germany

4 Department of General Surgery, Wilhelminen Hospital, Montleartstrasse 37, 1160 Vienna, Austria

5 Medical Faculty, Sigmund Freud University, Freudplatz 3, 1020 Vienna, Austria 
$4.7 \%$ for transverse incisions [2]. Although incisional hernia is a very common clinical manifestation, a substantial heterogeneity in patient selection and clinical practice does exist [3]. In meta-analyses, laparoscopic intraperitoneal onlay mesh (IPOM) was found to have lower wound complication rates compared with the open procedure [4-7]. However, the guidelines recommend the laparoscopic IPOM technique only for defects up to a maximum of $8-10 \mathrm{~cm}$ since, when used for larger defects, the recurrence rate is much higher than in open repair [8-11]. Meta-analyses of open repair of incisional hernias comparing the sublay with the onlay technique showed advantages in the recurrence and wound complication rates for retrorectal mesh placement [12]. Therefore, in an expert consensus guided by systematic review, the sublay technique was recommended as the optimal mesh location in open incisional hernia surgery [3]. But the panel also stated that onlay mesh location may be useful in certain settings [3]. What is meant by certain settings was not further explained in the expert consensus [3].

Therefore, in the following analysis of data from the Herniamed Registry, the group of patients operated on with the onlay technique was compared with those operated on with the sublay technique to identify differences in the patient- and hernia-related factors. Then, using propensity score matching, comparable patient collectives were formed and the results were compared.

\section{Materials and methods}

Herniamed is a multicenter, internet-based hernia registry $[13,14]$ into which 644 participating hospitals and surgeons engaged in private practice in Germany, Austria, and Switzerland (status: January 5, 2018) have entered data prospectively on their patients who had undergone routine hernia repair and signed an informed consent agreeing to participate [15]. As part of the information provided to patients regarding participation in the Herniamed Registry and signing the informed consent declaration, all patients were informed that the treating hospital or medical practice would like to be informed about any problem occurring after the operation and that the patient had the opportunity to attend for clinical examination [15]. All postoperative complications occurring up to 30 days after surgery were recorded. On 1-year follow-up, postoperative complications were once again reviewed when the general practitioner and patient completed a questionnaire [15]. On 1-year follow-up, the general practitioner and patients were also asked about any recurrences, bulging, pain at rest, pain on exertion, and chronic pain requiring treatment [15]. If recurrences or chronic pain was reported by the general practitioner or patient, patients could be requested to attend clinical examination or radiologic tests [15]. A recent publication has provided impressive evidence of the role of patient-reported outcomes for both recurrence and chronic pain $[15,16]$.

The present analysis compares the prospective data collected for all patients with primary incisional hernias having undergone elective open repair in sublay or onlay technique. Inclusion criteria were valid minimum age of 16 years, incisional hernia, elective operation, and availability of data on 1-year follow-up (Fig. 1). In all, 7821 patients were enrolled between September 1, 2009, and December 1, 2016, (Fig. 1).

The demographic and patient-related parameters include age (years), gender, American Society of Anesthesiologists (ASA) score I, II, III, IV, BMI kg/m², and risk factors like chronic obstructive pulmonary disease (COPD), diabetes mellitus, aortic aneurysms, corticoid medication, immunosuppression, coagulopathy, smoking, antiplatelet medication, anticoagulant therapy, and preoperative pain. Hernia-related variables influencing the outcome included the hernia defect size according to the European Hernia Society (EHS) classification (W1 $<4 \mathrm{~cm}$, W2 $\geq 4-10 \mathrm{~cm}$, and $\mathrm{W} 3>10 \mathrm{~cm}$ ) [17] and hernia localization (medial, lateral, and combined) [17]. Hernia width was recorded during surgery based on intraoperative measurements [15]. The dependent variables were intraoperative, postoperative and general complication rates, complication-related reoperation rate, recurrence rate and rates of pain at rest, pain on exertion, and chronic pain requiring treatment [15].

All analyses were performed with the software SAS 9.4 (SAS Institute Inc., Cary, NY, USA) and intentionally calculated to a full significance level of $5 \%$, that is, they were not corrected in respect to multiple tests, and each $p$ value $\leq 0.05$ represents a significant result [15] .

The individual outcome and influencing variables (risk factors and complications) were summarized as global variables. A general, intra- or postoperative complication or risk factor was deemed to be present if at least one single item applied.

Propensity score matching is a suitable statistical method for formation of comparison groups from a very heterogeneous patient population. Persons with similar characteristics were assigned to the comparison groups and then compared with regard to the outcome variables. The propensity scores were calculated using a logistic regression model with selected matching variables. The following matching variables were selected: age in years, BMI $\left(\mathrm{kg} / \mathrm{m}^{2}\right)$, gender (male/female), risk factors (yes/no), ASA score (I, II, III, and IV), preoperative pain (yes, no, and unknown), defect size $(\mathrm{W} 1<4 \mathrm{~cm}, \mathrm{~W} 2 \geq 4-10 \mathrm{~cm}$, $\mathrm{W} 3>10 \mathrm{~cm}$ ), and EHS classification (medial, lateral, and combined). 
Fig. 1 Flowchart of patient inclusion

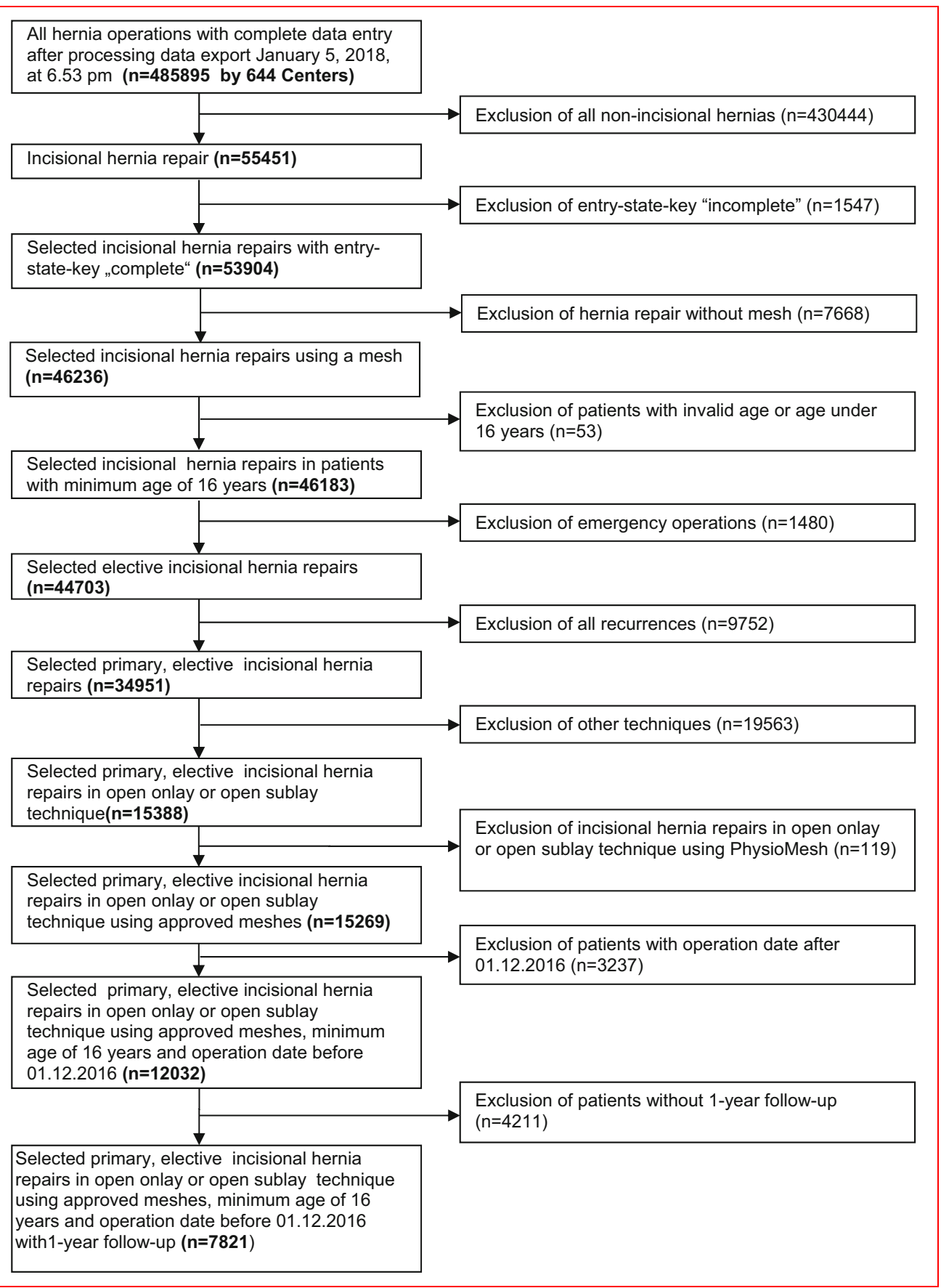

The robust greedy algorithm was used for matching applying a caliper of 0.5 standard deviation.

Unadjusted analyses were performed before matching for analysis of the operation techniques with regard to the matching parameters. This helped to obtain a description of the patient collective before matching. The asymptotic Chisquare test was used for categorical parameters and the robust $t$ test (Satterthwaite) for continuous parameters.

To assess the balance of the single matching parameters between comparison groups after matching, standardized differences are estimated. As a rule of thumb, a good balance between the groups and thus comparability is assured by a standardized difference of less than $10 \%$ $(<0.1)$.

The McNemar's test was performed to analyze the influence of the operation techniques on the outcome parameters (general, intra- and postoperative complications, complication-related reoperations, pain at rest, pain on exertion, chronic pain requiring treatment, and recurrence at 1-year follow-up) in the matched samples. 
Table 1 Results of the unadjusted tests of homogeneity between the operation techniques for the categorical matching variables before matching

\begin{tabular}{|c|c|c|c|c|c|}
\hline & \multicolumn{2}{|c|}{ Onlay } & \multicolumn{2}{|c|}{ Sublay } & \multirow{2}{*}{$p$} \\
\hline & $n$ & $\%$ & $n$ & $\%$ & \\
\hline \multicolumn{6}{|l|}{ Gender } \\
\hline Male & 484 & 47.27 & 3481 & 51.21 & \multirow[t]{2}{*}{0.018} \\
\hline Female & 540 & 52.73 & 3316 & 48.79 & \\
\hline \multicolumn{6}{|l|}{$\begin{array}{l}\text { Defect size (EHS } \\
\text { classification) }\end{array}$} \\
\hline $\mathrm{W} 1(<4 \mathrm{~cm})$ & 342 & 33.40 & 1620 & 23.83 & \multirow[t]{3}{*}{$<.001$} \\
\hline $\mathrm{W} 2(\geq 4-10 \mathrm{~cm})$ & 517 & 50.49 & 3728 & 54.85 & \\
\hline $\mathrm{W} 3(\geq 10 \mathrm{~cm})$ & 165 & 16.11 & 1449 & 21.32 & \\
\hline \multicolumn{6}{|l|}{ ASA score } \\
\hline I & 107 & 10.45 & 652 & 9.59 & \multirow[t]{3}{*}{0.545} \\
\hline II & 566 & 55.27 & 3865 & 56.86 & \\
\hline III/IV & 351 & 34.28 & 2280 & 33.54 & \\
\hline \multicolumn{6}{|l|}{ EHS classification } \\
\hline Combined & 107 & 10.45 & 531 & 7.81 & \multirow[t]{3}{*}{$<.001$} \\
\hline Lateral & 277 & 27.05 & 1132 & 16.65 & \\
\hline Medial & 640 & 62.50 & 5134 & 75.53 & \\
\hline \multicolumn{6}{|l|}{ Risk factors } \\
\hline \multicolumn{6}{|l|}{ Total } \\
\hline Yes & 426 & 41.60 & 2987 & 43.95 & \multirow[t]{2}{*}{0.158} \\
\hline No & 598 & 58.40 & 3810 & 56.05 & \\
\hline \multicolumn{6}{|l|}{ COPD } \\
\hline Yes & 100 & 9.77 & 749 & 11.02 & \multirow[t]{2}{*}{0.229} \\
\hline No & 924 & 90.23 & 6048 & 88.98 & \\
\hline \multicolumn{6}{|l|}{ Diabetes } \\
\hline Yes & 151 & 14.75 & 925 & 13.61 & \multirow[t]{2}{*}{0.325} \\
\hline No & 873 & 85.25 & 5872 & 86.39 & \\
\hline \multicolumn{6}{|l|}{ Aortic aneurysm } \\
\hline Yes & 7 & 0.68 & 146 & 2.15 & \multirow[t]{2}{*}{0.002} \\
\hline No & 1017 & 99.32 & 6651 & 97.85 & \\
\hline \multicolumn{6}{|c|}{ Immunosuppression } \\
\hline Yes & 17 & 1.66 & 149 & 2.19 & \multirow[t]{2}{*}{0.271} \\
\hline No & 1007 & 98.34 & 6648 & 97.81 & \\
\hline \multicolumn{6}{|l|}{ Corticoids } \\
\hline Yes & 16 & 1.56 & 113 & 1.66 & \multirow[t]{2}{*}{0.815} \\
\hline No & 1008 & 98.44 & 6684 & 98.34 & \\
\hline Smoking & & & & & \\
\hline Yes & 106 & 10.35 & 899 & 13.23 & 0.010 \\
\hline No & 918 & 89.65 & 5898 & 86.77 & \\
\hline Coagulopathy & & & & & \\
\hline Yes & 28 & 2.73 & 160 & 2.35 & 0.459 \\
\hline No & 996 & 97.27 & 6637 & 97.65 & \\
\hline ASS/Plavix antipla & ation & & & & \\
\hline Yes & 122 & 11.91 & 935 & 13.76 & 0.108 \\
\hline No & 902 & 88.09 & 5862 & 86.24 & \\
\hline
\end{tabular}

Table 1 continued

\begin{tabular}{|c|c|c|c|c|c|}
\hline & \multicolumn{2}{|c|}{ Onlay } & \multicolumn{2}{|c|}{ Sublay } & \multirow[t]{2}{*}{$p$} \\
\hline & $n$ & $\%$ & $n$ & $\%$ & \\
\hline \multicolumn{6}{|c|}{ Anticoagulation therapy } \\
\hline Yes & 37 & 3.61 & 227 & 3.34 & 0.651 \\
\hline No & 987 & 96.39 & 6570 & 96.66 & \\
\hline \multicolumn{6}{|c|}{ Preoperative pain } \\
\hline Yes & 560 & 54.69 & 3926 & 57.76 & 0.176 \\
\hline No & 372 & 36.33 & 2312 & 34.02 & \\
\hline Unknown & 92 & 8.98 & 559 & 8.22 & \\
\hline
\end{tabular}

Furthermore, odds ratio estimates (adjusted for matched samples) and their corresponding $95 \%$ confidence intervals are given.

\section{Results}

The sublay technique was used in 6797 (86.9\%) and the onlay technique in $1024(13.1 \%)$ cases, attesting to the high degree of selection applied to the use of the onlay technique. In the unadjusted analysis of comparison collectives before matching, no significant differences were identified for age (onlay $63.8 \% \pm 13.1 \%$ vs. sublay $63.9 \% \pm 12.7 \%$; $p=0.838$ ), BMI (onlay $29.0 \% \pm 5.8 \%$ vs. sublay $29.0 \% \pm 5.6 \% ; p=0.949$ ), preoperative pain (onlay VAS $3.7 \pm 1.8$ vs. sublay VAS $3.6 \pm 1.8 ; p=0.069)$, and ASA score or risk factors (Table 1). However, it was revealed that for the onlay technique highly significantly more hernias with small EHS classifications (W1 $<4 \mathrm{~cm}$ : onlay $33.4 \%$, sublay $23.8 \%$ ) as well as lateral and combined defects (lateral: onlay 27.1\%, sublay $16.7 \%$; combined: onlay $10.5 \%$, sublay $7.8 \%$ ) were repaired. Equally, the proportion of women operated on with the onlay technique was significantly higher. As such, predominantly more small and lateral/combined defects as well as female patients were selected for the onlay technique. Therefore, there is evidence of a selected patient collective since the onlay technique was indicated much more rarely than the sublay technique. Accordingly, the unadjusted results do not lend themselves to comparison.

Propensity score matching of the 1024 open onlay operations to the 6797 patients with open sublay operation was successfully applied for 1016 (99.2\%) patient pairs.

The standardized differences in the matching variables both before (original sample) and after matching (matched samples) are given in Tables 2 and 3. The difference is less than $10 \%$ for all matching variables, attesting to the good balance of the variables between the groups. 
Table 2 Standardized differences of continuous matching parameters before and after matching

\begin{tabular}{|c|c|c|c|c|}
\hline & \multirow[t]{2}{*}{ Onlay } & \multirow[t]{2}{*}{ Sublay } & \multicolumn{2}{|l|}{ STD } \\
\hline & & & Matched sample & Original sample \\
\hline \multicolumn{5}{|l|}{ Age (years) } \\
\hline Mean \pm STD & $63.9 \pm 13.1$ & $63.5 \pm 12.6$ & 0.032 & 0.007 \\
\hline \multicolumn{5}{|l|}{ BMI } \\
\hline Mean \pm STD & $29.0 \pm 5.8$ & $28.8 \pm 5.8$ & 0.026 & 0.002 \\
\hline
\end{tabular}

Table 3 Standardized differences of the categorical matching parameters before and after matching

\begin{tabular}{|c|c|c|c|c|c|c|}
\hline & \multicolumn{2}{|c|}{ Onlay } & \multicolumn{2}{|c|}{ Sublay } & \multicolumn{2}{|l|}{ STD } \\
\hline & $n$ & $\%$ & $n$ & $\%$ & Matched sample & Original sample \\
\hline Male & 482 & 47.44 & 514 & 50.59 & 0.063 & 0.079 \\
\hline Preoperative pain & 554 & 54.53 & 556 & 54.72 & 0.004 & 0.062 \\
\hline No preoperative pain & 370 & 36.42 & 382 & 37.60 & 0.024 & 0.048 \\
\hline Unknown preoperative pain & 92 & 9.06 & 78 & 7.68 & 0.050 & 0.027 \\
\hline ASA score I & 106 & 10.43 & 108 & 10.63 & 0.006 & 0.029 \\
\hline ASA score II & 563 & 55.41 & 581 & 57.19 & 0.036 & 0.032 \\
\hline ASA score III-IV & 347 & 34.15 & 327 & 32.19 & 0.042 & 0.015 \\
\hline $\mathrm{W} 1(<4 \mathrm{~cm})$ & 338 & 33.27 & 344 & 33.86 & 0.013 & 0.213 \\
\hline $\mathrm{W} 2(\geq 4-10 \mathrm{~cm})$ & 513 & 50.49 & 511 & 50.30 & 0.004 & 0.087 \\
\hline $\mathrm{W} 3(\geq 10 \mathrm{~cm})$ & 165 & 16.24 & 161 & 15.85 & 0.011 & 0.134 \\
\hline EHS classification medial & 741 & 72.93 & 736 & 72.44 & 0.011 & 0.254 \\
\hline EHS classification lateral & 382 & 37.60 & 387 & 38.09 & 0.010 & 0.285 \\
\hline Risk factors & 423 & 41.63 & 401 & 39.47 & 0.044 & 0.047 \\
\hline
\end{tabular}

The results of analysis of the various outcome parameters for the sublay and onlay operation techniques are shown in Table 4. No systematic deviation was identified in the outcome parameters between the two operation techniques. All confidence intervals cross one. Hence, no advantage or disadvantage can be identified for any outcome variable of the two operation techniques. Therefore, for a selected patient collective with predominantly small and lateral or combined defects, and more female patients, similar results were obtained for the sublay and onlay techniques.

The fact that for women the onlay technique was used more often led us to perform an additional analysis. That showed that neither for the onlay nor the sublay technique was there any significant differences between men and women with regard to the hernia defect width or defect localization. But there were significant differences between men and women where the risk factors were concerned. For example, for women operated on in the sublay technique, the risk factor rate was $40.7 \%$ versus $47.1 \%$ for men $(p<0.001)$ and, likewise, for the onlay technique that was
$38.0 \%$ versus $45.7 \%$ ( $p=0.013$ ). Hence, the lower rate of risk factors in women appears to have resulted in the onlay technique being indicated more often for them.

A further additional analysis looked for any differences between the technical details of the two techniques. That showed that defect closure at $57.8 \%$ was significantly more common in the onlay technique than in the sublay technique with $46.2 \%(p<0.001)$. Drains were used more often for sublay repair $(84.0 \%$ versus $80.1 \% ; p=0.012$ ). Mesh fixation was done significantly more often in the onlay technique with suture alone $(94.0 \%$ vs. $89.5 \%$; $p<0.001)$ or tackers $(3.0 \%$ vs. $0.6 \% ; p<0.001)$ and significantly less often with glue $(0.9 \%$ vs. $4.6 \%$; $p<0.001)$ or a combination thereof $(2.1 \%$ vs. $5.3 \%$; $p<0.001$ ). Numerous meshes were used in a proportion of $<5 \%$ of cases, at $58.7 \%$ in the onlay technique and $55.2 \%$ in the sublay technique. Only for the Ultrapro (onlay $29.2 \%$, sublay $31.0 \%$ ), Parietene ProGrip (onlay $8.7 \%$, sublay $7.2 \%$ ), and the Parietex ProGrip (onlay 3.4\%, sublay $6.7 \%$ ) was the proportion higher. 
Table 4 Proportion of cases in which the respective operation technique would have had disadvantages $(n=1.016$ matched pairs)

\begin{tabular}{|c|c|c|c|c|c|c|}
\hline & \multicolumn{2}{|c|}{ Disadvantages } & \multirow[t]{2}{*}{$p$ value } & \multicolumn{3}{|c|}{ OR estimate for matched samples } \\
\hline & Onlay & Sublay & & OR & & \\
\hline Intraoperative complications & 1.67 & 1.28 & 0.585 & 1.308 & 0.598 & 2.928 \\
\hline General complications & 2.46 & 2.95 & 0.590 & 0.833 & 0.470 & 1.466 \\
\hline Postoperative complications & 8.56 & 7.78 & 0.587 & 1.101 & 0.803 & 1.513 \\
\hline Complication-related reoperation & 3.74 & 4.13 & 0.738 & 0.905 & 0.568 & 1.438 \\
\hline Recurrence on 1-year follow-up & 5.31 & 4.13 & 0.261 & 1.286 & 0.843 & 1.972 \\
\hline Pain on exertion on 1-year follow-up & 15.94 & 15.35 & 0.779 & 1.038 & 0.828 & 1.302 \\
\hline Pain at rest on 1-year follow-up & 10.53 & 10.53 & 1.000 & 1.000 & 0.758 & 1.320 \\
\hline Chronic pain requiring treatment on 1 -year follow-up & 7.48 & 7.28 & 0.935 & 1.027 & 0.736 & 1.434 \\
\hline
\end{tabular}

\section{Discussion}

This analysis of data from the Herniamed Registry first of all demonstrates that the onlay technique is used only rarely, and thus selectively, compared to the sublay technique for repair of incisional hernia. When it is used, the proportion of lateral or combined defects, smaller hernias, and the proportion of women are significantly higher than in the sublay collective. Women in both the onlay and sublay groups were found to have a lower rate of risk factors. There were no differences between women and men with regard to defect sizes or defect localizations.

After propensity score matching of this selected onlay collective with the sublay collective, no significant difference is then observed between the use of the sublay and onlay techniques for repair of incisional hernias with regard to any of the outcome criteria, i.e., intra-, postoperative and general complications, complication-related reoperation, pain at rest, pain on exertion, chronic pain requiring treatment, and recurrence on 1-year follow-up.

This thus suggests that surgeons have properly evaluated the indication for the onlay operation. In studies with a comparatively low selection-based proportion of onlay operations for repair of incisional hernias, there was likewise a lower postoperative complication and recurrence rate [18-21]. Surgical experience, selective indications, and smaller defects seem to reduce the postoperative complication and recurrence rates for the onlay technique in incisional hernia repair [18-21]. Furthermore, the postoperative wound complication rate can be reduced through preventive technical measures such as defect closure, drains, refixation of the subcutaneous tissue to the abdominal wall with low-thrombin fibrin sealant, and abdominal binders [21]. In the present patient collective defect, closure was significantly more common in the onlay technique than in the sublay technique. Drains were used in around $80 \%$ of cases for both techniques.
Therefore, future studies on the onlay technique in incisional hernia repair should involve selected indications, a standardized surgical technique by experienced surgeons, and incorporation of preventive measures against seroma formation [21] since in a qualitative systematic review of all published studies on the onlay technique the mean postoperative complication rate was $33.5 \%$ (range 5-76\%). That high postoperative complication rate contraindicates the routine use of the onlay technique [21]. The onlay technique should not be used routinely, in particular, for large midline incisional hernias [22] because the postoperative complication rate is much too high compared with the sublay operation [21].

Registry studies have certain limitations. Voluntary data submission is dependent on the motivation of the participating surgeons to achieve complete data capture [23]. It is not always possible to definitely rule out a reporting bias with underreporting [23]. Therefore, all findings are subjected to critical scrutiny on the basis of the literature data.

In summary, it has been noted that subject to appropriate selection of smaller and lateral defects in predominant women with a lower risk profile, the onlay technique can be used while assuring similar outcomes to the sublay operation. Of paramount importance here are the surgeon's experience and the use of preventive measures (defect closure, drain, abdominal binder, and fibrin glue) for avoidance of postoperative complications. For larger defects, especially at the midline, better results can be obtained with other operation techniques (sublay and transversus abdominis release) [24, 25]. The registry data demonstrate that the onlay technique can be safely performed in selected cases.

Acknowledgements Funding was provided by Bard, Karlsruhe, Germany (Grant to fund the Herniamed Registry), Johnson and Johnson, Norderstedt, Germany (Grant to fund the Herniamed Registry), Dahlhausen, Cologne, Germany (Grant to fund the Herniamed Registry), MenkeMed, Munich, Germany (Grant to fund the 
Herniamed Registry), pfm medical, Cologne, Germany (Grant to fund the Herniamed Registry), B Braun, Tuttlingen, Germany (Grant to fund the Herniamed Registry), and Karl Storz, Tuttlingen, Germany (Grant to fund the Herniamed Registry)

Open Access This article is distributed under the terms of the Creative Commons Attribution 4.0 International License (http://creativecommons. org/licenses/by/4.0/), which permits unrestricted use, distribution, and reproduction in any medium, provided you give appropriate credit to the original author(s) and the source, provide a link to the Creative Commons license, and indicate if changes were made.

\section{References}

1. Bosanquet DC, Ansell J, Abdelrahman T, Cornish J, Harries R, Stimson A et al (2015) systematic review and meta-regression of factors affecting midline incisional hernia rates: analysis of 14.618 patients. PLOS ONE 10(9):e0138745. https://doi.org/10. 1371/journal.pone.0138645

2. Le Huu NR, Mege D, Ouaissi M, Sielezness I, Sastre B (2012) Incidence and prevention of ventral incisional hernia. J Visc Surg 149:e3-e14. https://doi.org/10.1016/jviscsurg.2012.05.004

3. Liang MK, Holihan JL, Itani K, Alawadi ZM, Flores Gonzales JR, Askenasy EP et al (2017) Ventral hernia management: expert consensus guided by systematic review. Ann Surg 265(1):80-89. https://doi.org/10.1097/SLA.0000000000001701

4. Chalabi AI, Larkin J, Mehigan B, McCormich P (2015) A systematic review of laparoscopic versus open abdominal incisional hernia repair, with meta-analysis of randomized controlled trials. Int J Surg 20:65-74. https://doi.org/10.1016/j.ijsu.2015.05.050

5. Awaiz A, Rahman F, Hossain MB, Yunus RM, Khan S, Memon B, Memon MA (2015) Reply to comment to meta-analysis and systematic review of laparoscopic versus open mesh repair for elective incisional hernia. Hernia 19:1027-1029. https://doi.org/ 10.1007/s10029-15-1432-z

6. Jensen K, Jorgensen LN (2015) Comment to: Meta-analysis and systematic review of laparoscopic versus open mesh repair for elective incisional hernia. Awaiz A et al. Hernia 2015; 19:449-463. Hernia 19:1025-1026. https://doi.org/10.1007/ s10029-15-1412-3

7. Awaiz A, Rahman F, Hossain MB, Yunus RM, Khan S, Memon B, Memon MA (2015) Meta-analysis and systematic review of laparoscopic versus open mesh repair for elective incisional hernia. Hernia 19:449-463. https://doi.org/10.1007/s10029-151351-z

8. Bittner R, Bingener-Casey J, Dietz U, Fabian M, Ferzli GS, Fortelny RH, Köckerling F et al (2014) Guidelines for laparoscopic treatment of ventral and incisional abdominal wall hernias (International Endohernia Sociaty (EHS)-part 1). Surg Endosc 28:2-29. https://doi.org/10.1007/s00464-013-3170-6

9. Bittner R, Bingener-Casey J, Dietz U, Fabian M, Ferzli GS, Fortelny RH, Köckerling F et al (2014) Guidelines for laparoscopic treatment of ventral and incisional abdominal wall hernias (International Endohernia Sociaty (EHS)-Part 2). Surg Endosc 28:353-379. https://doi.org/10.1007/s00464-013-3171-5

10. Bittner R, Bingener-Casey J, Dietz U, Fabian M, Ferzli GS, Fortelny RH, Köckerling F et al (2014) Guidelines for laparoscopic treatment of ventral and incisional abdominal wall hernias (International Endohernia Sociaty (EHS)-Part 3). Surg Endosc 28:380-404. https://doi.org/10.1007/s00464-013-3172-4

11. Earle D, Roth JS, Saber A, Haggerty S, Bradley JF III, Fanelli R et al (2016) SAGES guidelines for laparoscopic ventral hernia repair. Surg Endosc 30:3163-3183. https://doi.org/10.1007/ s00464-016-5072-x

12. Timmermans L, de Goede B, van Dijk SM, Kleinrensink GJ, Jeekel J, Lange JF (2014) Meta-analysis of sublay versus onlay mesh repair in incisional hernia surgery. Am J Surg 207:980-988. https://doi.org/10.1016/j.amjsurg.2013.08.030

13. Stechemesser B, Jacob DA, Schug-Paß C, Köckerling F (2012) Herniamed: an internet-based registry for outcome research in hernia surgery. Hernia 16:269-276. https://doi.org/10.1007/ s10029-012-0908-3

14. Kyle-Leinhase I, Köckerling F, Jorgensen LN, Montgomery A, Gillion JF, Rodriquez JAP et al (2012) comparison of hernia registries: the CORE project. Hernia 2012:2261-2575. https://doi. org/10.1007/s10029-017-1724-6

15. Köckerling F, Simon T, Hukauf M, Hellinger A, Fortelny R, Reinpold W, Bittner R (2018) The importance of registries in the postmarketing surveillance of surgical meshes. Ann Surg 268(6):1097-1104. https://doi.org/10.1097/SLA.0000000000002326

16. Baucom RB, Ousley J, Feurer ID, Beveridge GB, Pierce RA, Holzman MD, Sharp KW, Poulose BK (2016) Patient reported outcomes after incisional hernia repair-establishing the ventral hernia recurrence inventory. Am J Surg 212:81-88. https://doi. org/10.1016/j.amsurg.2015.06.007

17. Muysoms FE, Miserez M, Berrevoet F, Campanelli G, Champault DD, Chelala E et al (2009) Classification of primary and incisional abdominal wall hernias. Hernia 13:407-414. https://doi. org/10.1007/s10029-009-0518-x

18. Abdollahi A, Maddah GH, Mehrabi BM, Jangjoo A, Froghani MN, Sharbaf N (2010) Prosthetic incisional hernioplasty: clinical experience with 354 cases. Hernia 14:569-573. https://doi.org/10. 1007/s10029-010-0685-9

19. Andersen LPH, Klein M, Gögenur I, Rosenberg J (2009) Longterm recurrence and complication rates after incisional hernia repair with the open onlay technique. BMC Surg 9:6. https://doi. org/10.1186/1471-2482-9-6

20. Hopson SB, Miller LE (2015) Open ventral hernia repair using ProGrip self-gripping mesh. Int J Surg 23:137-140. https://doi. org/10.1016/j.ijsu.2015.09.069

21. Köckerling F (2018) Onlay technique in incisional hernia repair: a systematic review. Front Surg 5:71. https://doi.org/10.3389/ fsurg.2018.00071.eCollection2018

22. De Vries Reilingh TS, van Geldere D, Langhorst B, de Jong D, van der Wilt GJ, van Goor H, Bleichrodt RP (2004) Repair of large midline incisional hernias with polyproplene mesh: comparison of three operative technique. Hernia 8:56-59. https://doi. org/10.1007/s10029-003-0170-9

23. Mandavia R, Knight A, Phillips J, Mossialos E, Littlejohns P, Schilder A (2017) What are the essential features of a successful surgical registry? A systematic review. BMJ Open 7:e017373. https://doi.org/10.1136/bmjopen-2017-017373

24. Köckerling F, Schug-Pass C, Scheuerlein H (2018) What is the current knowledge about sublay/retro-rectus repair of incisional hernias? Front Surg 13(5):47. https://doi.org/10.3389/fsurg.2018. 00047

25. Scheuerlein H, Thiessen A, Schug-Pass C, Köckerling F (2018) What do we know about component separation techniques for abdominal wall hernia repair? Front Surg 27(5):24. https://doi. org/10.3389/fsurg.2018.00024

Publisher's Note Springer Nature remains neutral with regard to jurisdictional claims in published maps and institutional affiliations. 